Касимова Улдана Куралбаевна, м.э.н., инспектор Казахский национальный педагогический университет имени Абая г. Алматы, ORCID ID 0000-0002-0675-2356, E-mail: ulydana@mail.ru

Джумагалиев Руслан, Председатель РОО «Қазақ тілі қоғамы» имени К. Мандоки, г. Атырау, Казахстан

\title{
НОВЫЙ ВЗГЛЯД НА ТЕОРИЮ ПРОИСХОЖДЕНИЯ ЭНЕРГОРЕСУРСОВ
}

\author{
Kassimova Uldana Kuralbaevna, M.Ec., coordinator \\ Abai Kazakh national pedagogical university \\ Almaty, Kazakhstan, ORCID ID 0000-0002-0675-2356, E-mail: ulydana@mail.ru \\ Dzhumagaliev Ruslan \\ President, RPA «Kazakh TiliKogamy» named after K. Mandoki \\ Atyrau, Kazakhstan
}

\section{A NEW VIEW OF THE THEORY OF ENERGY RESOURCES ORIGIN}

Annotation: Finding fuel and energy reserves is one of the pressing problems of the modern world. It is of great importance given the rise in the global demographic indicators. The main objective of this work - to conduct exploratory work on the structures formed as a result of geological activity flowing rivers, in the canyons, catacombs, caves and peninsulas, as well as in swamps, waterfalls and in forests. In this research work we put forward a new theory about the origin of petroleum and coal deposits, which is related to geological activities of right, wrong and hybrid rivers.

Keywords: river; flow; geology; southern hemisphere; northern hemisphere;right, wrong and hybrid rivers.

Аннотация: Одним из актуальных проблем современности является определение топливно-энергетических запасов. Это очень важно в связи с ростом демографических показателей на нашей планете. Главная иель данной работы - провести поисковые работы на структурах, образовавшихся в результате геологической деятельности текучих рек, т.е в каньонах, катакомбах, пещерах, полуостровах, а также в болотах, водопадах и в лесных массивах. В данной научной работе мы выдвигаем новую теорию о происхождении нефтяных и угольных месторождений, которая связана геологической деятельностью правильных, неправильных и комбиннированных рек.

Ключевые слова: река; течение; геология; южное полушарие; северное полушарие; правильные, неправильные и комбиннированные реки.

Одним из актуальных проблем современности является определение топливноэнергетических запасов.

Это очень важно в связи с ростом демографических показателей на нашей планете.

В настоящее время множество способов разведки полезных ископаемых, в том числе исследования космических снимков в комплексе с анализом геологических условий, структурометрический анализ и тематическое дешифрирование и другие. Эти методы позволяют прогнозировать залежи нефти, газа или месторождения других полезных ископаемых, причем на глубине до десяти километров и даже больше. С помощью

Геология энергоресурсы 
компьютерных программ обнаруживаются кольцевые структуры или особые непрямые признаки на спутниковых снимках и т.д.

Нефтяные месторождения приурочены к терригенным и карбонатным породам. Терригенные породы представлены песками и песчаниками. В зависимостиот размеров зерна песка терригенные коллекторы делятся на три: сверхкапиллярный, капиллярный, субкапиллярный.

Пески делятся на барханные и речные пески.

Барханные пески бывают мощными и занимают регионально большую территорию. Барханные пески образуются в результате условий жаркого климата в экваториальной части планеты, а также во время солнечного и галактического лета. В результате транспортирующей деятельности ветров, перемещаясь от одного места в другое образуются барханы.

Бархан-это ассиметричная и серповидная форма рельефа,которая расположена перпендикулярно к направлению ветра. Барханные пески, обычно не содержат нефтяных месторождений из-за их огромной площади и размеров, они полностью не покрываются покрышкой, в большинстве случаев они бывают региональные, водоносные. Из-за огромного размера площади, покрышки барханного песка не всегда бывают целыми, из-за разрушения покрышки тектоническими или гравитационными силами нефть,скопившаяся в этих песчаных коллекторах из-за хорошей проницаемости мигрирует на выше лежащие пласты. Такие региональные барханные пески в пределах Прикаспийской синеклизы были в нижней юре и альбском ярусе нижнего, и сеноманском ярусе верхнего мелового возраста. В этих песках нигде, в пределах Прикаспийской впадины, не обнаружены и испытаны нефтяные и газовые залежи. Размеры зерен барханных песков бывают почти однообразные.

Речные пески образуются в результате геологической деятельности текучих рек.

Реки, протекающие на всех континентах производят большую и эрозионную и аккумулятивную работу.

Движение воды в реках контролируется 3-мя факторами: 1) градиентом уклона русла; 2) расходом водного потока; 3) формой русла [1].

Текучие воды, образуются за счет весеннего таяния снегов и льдов с вершин горного массива. Спускаясь с вершины гор, они могут протекать на юг, на север, на восток и на запад. Все реки на Земле по направлению течения делятся на правильные, неправильные и комбинированные реки.

Правильными реками- называют те реки на Земле, которые протекают по направлению вектора центробежной силы Земли (Урал, Волга, Миссисипи) как показано на рисунке 1:

- с севера на юг на северном полушарии Земли;

- с юга на север на южном полушарии Земли;

- и все реки, которые протекают с востока на запад на Земном шаре.

Признаки правильных рек-течения воды турбулентные или винтовые, с большими скоростями, реки с западными течениями иногда высыхают. Русла рек могут быть не широкими, но бывают глубокими, вода в этих реках всегда бывает мутной. Эти реки имеют разрушительную деятельность в виде боковых и донных эрозий и образуют меандры (см. рисунок 2) и каньоны (Гранд Каньон-Миссисипи, Голубой Каньон, верхний Каньон Антилопы, Каньон на реке Белой) в зоне тектонических нарушений, а также там, где реки впадают в море от продукта эрозии и перенесенного материала аккумулируютсяпесчаные пляжные полуострова из песков (полуостров Пешной- река Урал, Казахстан, полуостров Флорида- река Миссисипи, США). Впоследствии, через

Геология энергоресурсы 
несколько миллионов лет, при благоприятных условиях, если песчаный полуостров будет иметь хорошую покрышку то могут образовыватьсязалежи нефти и газа пластового сводового типа и брахиантиклинальной и линейной структуры.

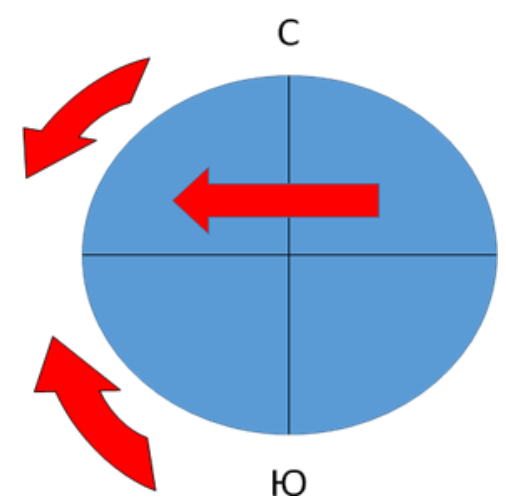

Рисунок 1 - Направление правильных рек

Правильные реки имеют разрушительную, транспортирующую и созидательную деятельность.

Разруиающая деятельность. Протекая по поверхности различных горных пород, турбулентные потоки воды производят преимущественно эродирующую работу. Река разрушает в двух направлениях: боковые эрозии, приводящие к расширению долины, и глубинные(донные) эрозии, выражающиеся во врезании русла. Если прибрежный грунт реки состоит из известняков, то промывая, протоки реки могут создавать каньоны, пещеры и катакомбы. Размеры пещеры и катакомбы зависят от угла падения известняковых пород, а также от предельного уровня морей и океанов.

Боковая эрозия. Реки не бывают прямыми и всегда образуют излучины [2].

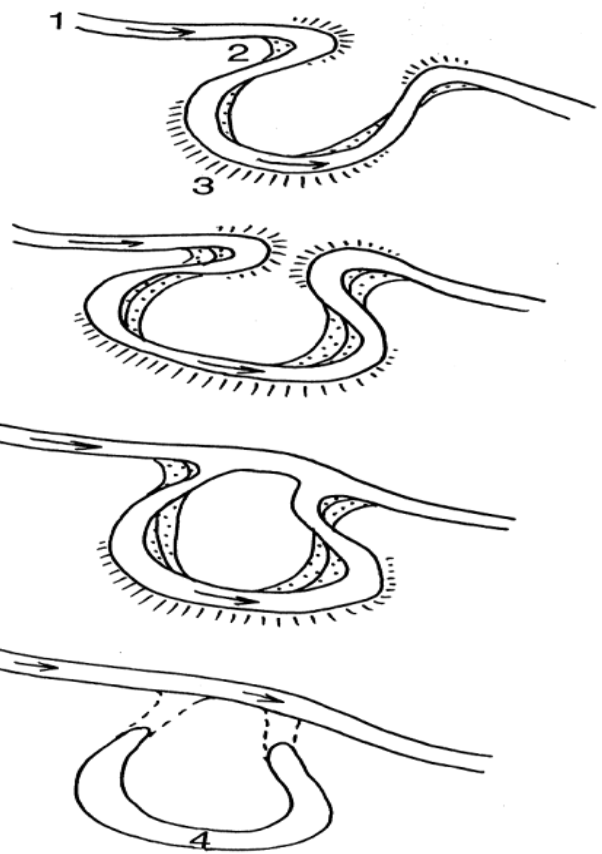

Рисунок 2 - Развитие меандры и перехват реки с образованием старицы

На отмелом берегу накапливается аллювий, а обрывистый берег все время подмывается:

1 -река; 2 -отмелый берег; 3 - приглубый берег; 4 - старииа 3 , с. 213]

Происходит это потому, что даже при прямолинейном русле распределение скоростей течения в потоке имеет винтообразный характер, благодаря которому попеременно размывается то правый, то левый берег. Поперечная циркуляция 
накладывается на общее поступательное движение воды и создает винтообразное движение по часовой стрелке при изгибе русла влево (если смотреть по течению) и против часовой стрелки при изгибе русла право. В результате боковой эрозии река образует меандры или старицы (см. рисунок 3).

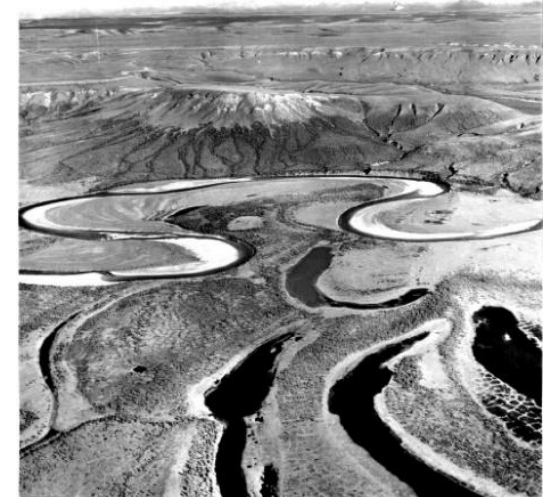

Рисунок 3 - Север Тунгусской синеклизы. Меандрирующая река и старицы [3, с. 214]

Глубинная эрозия. Скорость глубинной эрозии зависит от скорости течения воды, а скорость течения воды зависит от скорости горообразования и от предельного уровня морей и океанов: если скорость подъема континентальной части суши выше чем скорость глубинной эрозии, то образуются узкие, глубокие каньоны, иногда пещеры, как Голубой каньон и Каньон на реке Белой (см. рисунок 4), Гранд каньон на реке Миссисипи (см. рисунок 5).

Рисунок 4 - Каньон на реке Белой

[4]

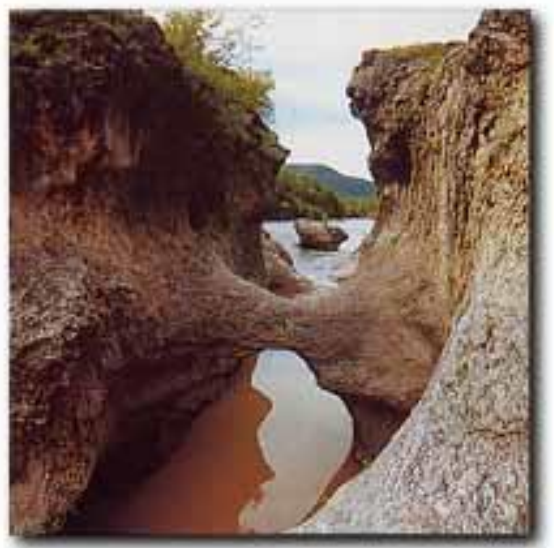

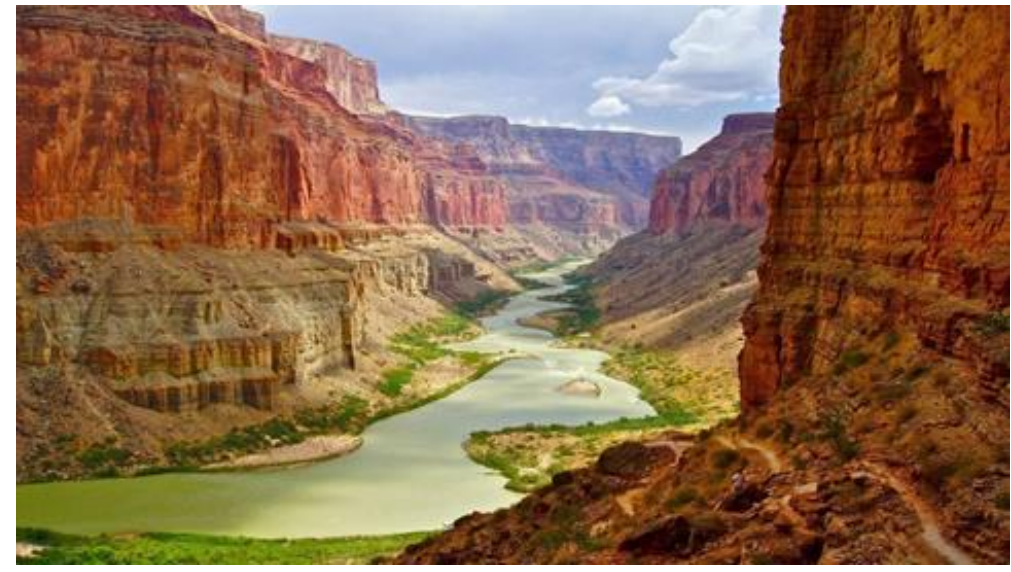

Рисунок 5 - Удивительный Гранд-Каньон в США [5]

Каньон на реке Белой. На южной окраине Хаджоха, там, где Белая грохочет в скальной теснине, с древних времен берега реки соединял природный каменный мост. При глубине каньона до 20 метров его длина составляет 350-400 метров.

Если скорость глубинной эрозии совпадает со скоростью горообразования, то каньоны бывают глубокими и широкими.

Если скорость подъема континента медленнее, чем уровень воды в морях или океанах, то реки бывают широкими и могут происходить боковые эрозии с меандрообразованием.

Все продукты глубинной и боковой эрозии выносятся на прибрежную часть морей и океанов и образуют песчанные полуострова, рукава и пляжи. Эти же речные пески 
образуют залежи нефти и газа пластово-сводового типа из-за небольшого объема, а также меньшеговоздействиявнешных факторов. Покрышка таких залежей меньше разрушается из-за тектонических и гравитационных сил.

Неправильными реками - называют те реки на Земле, которые протекают против направления вектора вращения центробежной силы Земли (Сибирские реки и реки Южной Америки) как показано на рисунке 6:

- с юга на север на северном полушарии Земли;

- с севера на юг на южном полушарии Земли;

- и все реки на Земле, которые протекают с запада на восток.

Рисунок 6 - Направление неправильных рек

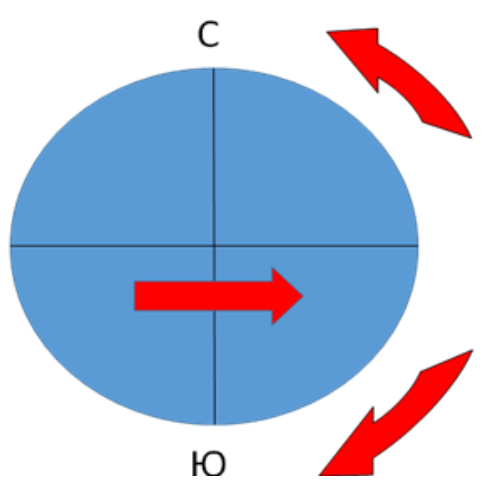

Рисунок 7 - Направление комбинированных рек $\mathrm{C}$

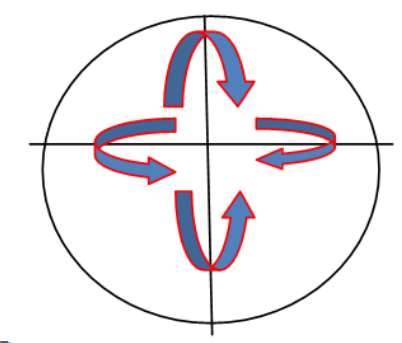

Ю

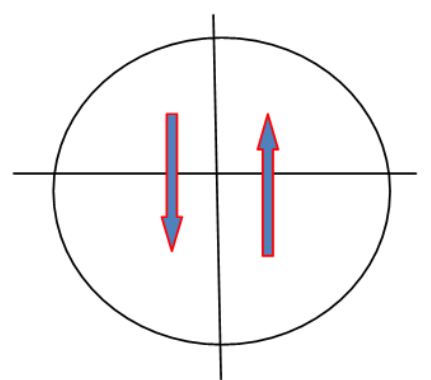

Признаки неправильных рек-течения воды в этих реках всегда бывают ламинарные, ширина реки может быть очень большой, иногда вода очень чистая и имеет разрушительнуюдеятельностьв виде наводнения и затопления прибрежных зон и может способствоватьсозданию лесных массивовкак тайга и джунгли.

Если на пути неправильных рек образуются разрывные дислокации ввиде сбросов или сдвигов, то реки образуют водопады.

Если на пути неправильных рек образуются разрывные дислокации ввиде взбросов или надвигов, то реки образуют болоты.

Если скорость образования складчатости и уровень роста болотных растенийодинаковы, то образуются торфы.

Развитие торфяного болота - это процесс накопления торфа в результате роста, отмирания и частичного разложения растительности в условиях избытка влаги и недостатка кислорода. Вся толща торфа в болоте называется торфяной залежью. Она имеет многослойное строение и содержит от 91 до 97\% воды. В торфе заключены ценные органические и неорганические вещества, поэтому его издавна используют в сельском хозяйстве, энергетике, химии, медицине и других областях. Впервые о торфе как о «горючей земле», пригодной для нагревания пищи, писал Плиний Старший в I в. н.э. В Голландии и Шотландии торф как топливо применяли в XII-XIII вв. Промышленное скопление торфа называют торфяным месторождением. Наибольшие промышленные запасы торфа имеют Россия, Канада, Финляндия и США [6, с. 179].

Если неправильные реки протекают через ровные местности, то из-за высокого уровня подпочвенной воды образуются лесные массивы.

Один из главных признаков неправильных рек - это то, что море, заходящее в реку и устья реки бывает очень широким (до 150 км-Амазонка). Из-замассовой гибели лесных и растительных насаждений прибрежных зон впоследствии могут образовываться болота, торф на поверхности Земли и через несколько миллионов лет - угольные месторождения.

Геология энергоресурсы 
Комбинированные реки -это реки пересекающие экваторы как показано на рисунке 7, например река Нил.Истоки рек на южном полушарии начинаются как правильные, и пересекая экватор они становятся неправильными и широкими, а также реки меняющие направления течения, например Конго, Меконг и. т. д.

Комбинированные реки- в зависимости от направления устья они могут быть и правильными и неправильными. Все характерные признаки для правильных и неправильных рек могут повторятся.

В условиях комбинированной реки, по нашему мнению, могут образоваться одновременно, где "правильное" течение - нефтяные месторождения, а где "неправильное" течение - угольные месторождения [7, с. 20].

Например, на острове Суматра обнаружены и нефтяные, и угольные месторождения Минас.

В своей работе мы попытались найти некоторую корреляцию между геофизическими процессами (в частности направлением вектора вращения центробежной силы Земли и скорости движения точек земного шара) и характеристики течения рек, которые немаловажную роль сыграли и будут играть в образовании нефтяных, газовых и угольных месторождений.

\section{Литература}

1. Электронная библиотека, Химия, Геологическая деятельность поверхностных текучих вод. Водные потоки производят огромную геологическую работу на поверхности суши [Электронный ресурс]. - 2018. - URL: https://studlib.info/himiya/1211920-geologicheskaya-deyatelnost-poverkhnostnykh-tekuchikhvod-vodnye-potoki-proizvodyat-ogromnuyu-geologicheskuyu-rabotu-na-poverkhnosti-sushil (дата обращения: 20.03.2018)

2. Геология, Эрозия [Электронный ресурс]. - 2010. - URL: http://www.mygeos.com/2010/01/16/eroziya (дата обращения: 20.01.2018)

3. Короновский Н.В. Общая геология. - М.: КДУ, 2014.-552 c.

4. Каньон по материалам книги Ю.Николаева и И.Бормотова«В краю гор и водопадов». [Электронный ресурс]. - 2018. - URL:https://www.svastour.ru/fisht/bv-m30cn.html(dama обращения: 22.02.2018)

5. Удивительный Гранд-Каньон в США [Электронный ресурс]. - 2016. - URL: http://chydesa-mira.ru/grand-kanyon-usa/(дата обращения: 24.03.2018)

6. Ананьева Е.Г., Мирнова С.С. Земля Полная энииклопедия. - М.:Эксмо, 2016. - 256 с.

7. Касимова У.К., Джумагалиев Р.С. Закономерность образования нефтяных и угольных месторождений на основе геологической и гидрологической деятельности. - Вестник КазНПУ им. Абая - Серия естественно-географческие науки. - Алмать: КазНПУ им. Абая, 2018. - №1 (55).-213 c. 